\title{
A comparative study of dietary fiber awareness, diseases \& drugs interaction in rural and urban areas of Bangladesh
}

\author{
Md. Tanvir Ahmed ${ }^{1}$, Sk. Shahinur Rahman ${ }^{1}$, Md. Shofikul Islam ${ }^{1}$, A. Y. K. Md. Masud Rana ${ }^{2}$, \\ Md. Hafizur Rahman,"
}

${ }^{1}$ Dept. of Applied Nutrition and Food Technology, Islamic University, Kushtia, Bangladesh

${ }^{2}$ Institute of Food and Radiation Biology, AERE, Savar, GPO Box 3787, Dhaka 1000, Bangladesh

Email address:

hrahman1973@gmail.com(M. H. Rahman), shahinanft@gmail.com(S. S. Rahman)

\section{To cite this article:}

Md. Tanvir Ahmed, Sk. Shahinur Rahman, Md. Shofikul Islam, A. Y. K. Md. Masud Rana, Md. Hafizur Rahman. A Comparative Study of Dietary Fiber Awareness, Diseases \& Drugs Interaction in Rural and Urban Areas of Bangladesh. Science Journal of Public Health. Vol. 1, No. 5, 2013, pp. 194-200. doi: 10.11648/j.sjph.20130105.12

\begin{abstract}
This comparative study represents the dietary fiber awareness among the two selected areas of Bangladesh, especially urban \& rural areas to detect the situation about knowledge, attitude and practices (KAP) of dietary fiber. This study is conducted among 100 people of two areas and shows that knowledge about dietary fiber is higher among the respondents of urban (96\%) than the respondents of rural (74\%). This study also represents that the attitude to prefer drugs, using laxative is higher among the respondents of urban area. But the curiosity of more intake of dietary fiber is higher among the rural people. This study also shows that among the rural people, the tendency of buying dietary fiber containing foods and intake of fresh dietary fiber foods is higher than urban. But practice of habiting of dietary fiber in fiber content foods stuffs is very much conscious among the respondents of both areas.
\end{abstract}

Keywords: Dietary Fiber, Knowledge, Rural and Urban People, Diseases

\section{Introduction}

Dietary fiber (DF) is the edible portions of plant foods (all polysaccharides and lignin, oligosaccharides, such as inulin, and resistant starches) which are not digested by human digestive enzymes in the GI tract and absorbed by the small intestine ${ }^{[1-5]}$. According to the Institute of Medicine (IOM), dietary fiber may be defined as non-digestible carbohydrates and lignin that are intrinsic and intact in plants, including the "plant non-starch polysaccharides (e.g., cellulose, pectin, gums, hemicelluloses, $\beta$-glucans, and fibers contained in oat and wheat bran), plant carbohydrates that are not recovered by alcohol precipitation (e.g., inulin, oligosaccharides, and fructans), lignin, and some resistant starch" ${ }^{\text {[6] }}$. American Association of Cereal Chemists (AACC) also defined dietary fiber as carbohydrate polymers with more than a three degree polymerization which are neither digested nor absorbed in the small intestine ${ }^{[7,1]}$. FAO/WHO also defined it as a polysaccharide with ten or more monomeric units which is not hydrolyzed by endogenous hormones in the small intestine ${ }^{[8]}$. Dietary fiber and whole grains are rich source of bioactive components including resistant starches, vitamins, minerals, phytochemicals such as phenolics, carotenoids, lignans, beta-glucan, inulin and antioxidants ${ }^{[1]}$. Depending on their solubility in water, DF can be classified in 2 major groups: soluble (natural gel-forming fibers eg. pectins, gums, mucilages, inulin-type fructans and some hemicelluloses) that are easily fermented by the microflora of the large intestine and insoluble (structural or matrix fibers eg. lignins, cellulose, and some hemicelluloses) that have bulking action but may only be fermented to a limited extent in the colon ${ }^{[9-10,5]}$. The recommended dietary fiber intakes for children and adults are $14 \mathrm{~g} / 1000 \mathrm{kcal}^{(11,9)}$. Koh-Banerjee et al. reported that daily intake of $40 \mathrm{~g}$ whole grain would reduce $1.1 \mathrm{lbs}$ weight whereas $20 \mathrm{~g} /$ day bran intake decrease $0.8 \mathrm{lbs}$ weight gain ${ }^{[12]}$. Diets high in soluble fiber decrease total and LDL cholesterol by increasing the rate of bile excretion ${ }^{[13-14]}$ but water-insoluble wheat fiber and cellulose have no effect unless they displace foods supplying saturated fats and cholesterol ${ }^{[15]}$. Increased intake of water soluble dietary fiber may reduce the risk for developing coronary heart disease ${ }^{[16-19]}$, stroke ${ }^{[20]}$, hypertension $^{[21]}$, diabetes ${ }^{[22-24]}$, obesity ${ }^{[25-26,9]}$. It is assumed that dietary fiber prevents certain gastrointestinal disorders $^{[27]}$ and obesity by inducing satiety and decreasing excess energy intake ${ }^{[28]}$. Furthermore, it also lowers blood 
cholesterol concentrations ${ }^{[29]}$, reduce blood pressure ${ }^{[30-33]}$, enhance insulin sensitivity ${ }^{[34-36]}$, promotes regularity ${ }^{[37]}$, aids in weight loss by increasing the ability to regulate energy intake $^{[38-40,1]}$, and appears to improve immune function ${ }^{[41]}$, decrease pro-inflammatory cytokines such as interleukin-18, C-Reactive protein $(\mathrm{CRP})^{[42-44]}$. Fruit and vegetable intake is associated with a lower risk for ischemic stroke ${ }^{[45]}$. In the colon, fermentable fibers increase bacterial mass with some acting as prebiotics to promote health-promoting bacteria such as lactobacilli and bifidobacteria ${ }^{[46]}$. Insoluble fibers are especially effective in increasing fecal mass and promoting regularity ${ }^{[47]}$. For long-term dietary fiber intake, the strength of the association between dietary fiber and all-cause mortality decreased with increasing age ${ }^{[48]}$. DF consumption affects the secretion of various gut hormones that may act as satiety factors ${ }^{[49]}$. Epidemiological and clinical studies demonstrate that consumption of dietary fiber and whole grain intake is inversely related to the development of several types of cancers including colorectal, small intestine, oral, larynx and breast ${ }^{[50,1]}$. Pectin plays an important role for the prevention of cancer. Nangia-Makker et al [51] proposed that citrus pectin binds and decrease tumor growth and cancerous cell migration in rats. Dietary fiber may also help to prevent cancer by rapid transit and elimination of the feces or may help to bind cancer producing chemicals and make them ineffective. There are several mode of actions for the activity of dietary fiber. i) dietary fiber (DF) interfere digestion in the small intestine and thus allowing it to enter in the large intestine where it is fermented and produce short chain fatty acids, which have anti-carcinogenic properties ${ }^{[52]}$. ii) DF increases fecal bulking and viscosity, thus it takes less time between potential carcinogens and mucosal cells. iii) It helps to bind between bile acids and carcinogens. iv) DF also increases antioxidant. v) DF may increase the amount of estrogen excreted in the feces due to an inhibition of estrogen absorption in the intestines ${ }^{[53]}$. Some studies have been shown that there are no relation between diabetes and soluble fiber ${ }^{[54-56]}$. Jenkins et al. ${ }^{[57]}$ also proposed that wheat bran had no effect on glycemic control in diabetic patient. A high dietary fiber intake (60gm/day) can produce abnormal distension and pain, flatulence and diarrhea and with a high phytate content. Again a high dietary fiber intake requires a high intake fluid intake. Not consuming enough fluid with dietary fiber can leave the stool very hard making lamination difficult and painful. Intestinal blockage has occurred in people who consume great amounts of wheat bran and oat bran. Large amount of dietary fiber can also bind important minerals (especially calcium, zinc, iron) and make them less available to the body. High fiber diets can decrease the absorption of iron $(\mathrm{Fe})$. As a result pregnant woman and young children and other groups are at risk of anemia. Most developed countries people intake little amount of dietary fiber as a result they suffer many diseases such as constipation, appendicitis, piles, diverticulosis, irritable bowel, obesity, hyper tension, especially constipation and piles. In spite of a lot of progress done for the elimination of dietary fiber less intake disorders in Bangladesh, there are no specific information about the knowledge attitude and practice (KAP) of dietary fiber of the whole country. To reduce prevalence of constipation, piles, KAP are most important program with other suitable programs. So, the general objective of this study was to assess the situation of knowledge, attitude \& practices (KAP) of dietary fiber in selected urban \& rural areas of Bangladesh.

\section{Methodology}

This study was conducted in 100 people of all socioeconomic groups living in urban \& rural areas of Bangladesh within the time $16^{\text {th }}$ September to $15^{\text {th }}$ December 2012. Among the total study population 50 people were collected randomly from urban and another 50 were from rural areas.

Data collection: A pretest questionnaires including knowledge about dietary fiber, their sources, deficiency disorder, relationship between dietary fiber and mineral absorption and problems of excess intake of dietary fiber were modified and standardized to collect the data. Statistical package for social science (SPSS) was used for entry and data analysis. Entry errors were checked and corrected. Microsoft word was used for graphs and chart.

\section{Results}

In our study, total 100 respondents were randomly selected from urban and rural areas and each area contain equal number of respondents.

Table 1 Shows, most of the respondents were in the age group between 21-30 years and the percentage were 55\% where $56 \%$ were urban people. In our study, we consider below 20 to up 41 years aged person as a sample people.

Table 2 represents, $60 \%$ people were in middle class where $70 \%$ people lived in urban areas. On the other hand, $15 \%$ and $25 \%$ people were high and low socio-economic status respectively.

This table also shows that $67 \%$ of the respondents were healthy where $21 \%$ were under weight and $12 \%$ were over weight. Only $8 \%$ obese people lived in rural areas and intake less dietary fiber.

Table also depicts $96 \%$ of the urban people gave the correct answer in compare to rural people when asked them about dietary fiber but $15 \%$ people have no knowledge about fiber. On the other hand, $42 \%$ people have knowledge about the role of dietary fiber in human body in all stages of life especially in the disorder like constipation and obesity but $58 \%$ have no idea. $85 \%$ people comments carrots, vegetables, fruits and wheat as a source of dietary fiber where $11 \%$ indicate milk, meat and fish. Only 4\% people told sugar, rice and water are the source of dietary fiber. Knowledge about the sources of dietary fiber was higher among the urban people (94\%) than rural people (76\%). 
Table1: Distribution of the respondents by ages.

\begin{tabular}{llll}
\hline Age in year (range) & Urban (\%) & Rural (\%) & Total (\%) \\
\hline $20 \leq$ & $11(22)$ & $10(20)$ & $21(21)$ \\
$21-30$ & $28(56)$ & $27(54)$ & $55(55)$ \\
$31-40$ & $5(10)$ & $6(12)$ & $11(11)$ \\
$\geq 41$ & $5(10)$ & $7(14)$ & $12(12)$ \\
Total & $50(100)$ & $50(100)$ & $100(100)$ \\
\hline
\end{tabular}

Table3: Distribution of the respondents based on their knowledge about common problems due to dietary fiber.

\begin{tabular}{|c|c|c|c|}
\hline Characteristics & Urban (\%) & Rural (\%) & Total (\%) \\
\hline \multicolumn{4}{|c|}{ Knowledge about common disordered } \\
\hline $\begin{array}{l}\text { Constipation, CVD, } \\
\text { Obesity, Piles }\end{array}$ & $45(90)$ & $40(80)$ & $85(85)$ \\
\hline Scurvy & $2(4)$ & $3(6)$ & $5(5)$ \\
\hline Peptic Ulcer & $1(2)$ & $2(4)$ & $3(3)$ \\
\hline Diarrhea & $2(4)$ & $5(10)$ & $7(7)$ \\
\hline \multicolumn{4}{|c|}{ Knowledge of the problems occur excess intake of dietary fiber } \\
\hline Diarrhea & $30(60)$ & $14(28)$ & $44(44)$ \\
\hline Loss of appetite & $4(8)$ & $7(14)$ & $11(11)$ \\
\hline Cancer & $1(2)$ & $1(2)$ & $2(2)$ \\
\hline Gas formation & $15(30)$ & $28(56)$ & $43(43)$ \\
\hline
\end{tabular}

Surprisingly, only $21 \%$ people have the knowledge about the daily requirements of dietary fiber but in compare with urban people, $84 \%$ rural people have no knowledge about daily requirements. This table also shows that $70 \%$ people declared dietary fiber is essential for all age groups where $9 \%, 17 \%$ and $4 \%$ people told childhood, pregnancy and lactating period respectively.

the problems occur due to excess intake of dietary fiber in human body in all the stages of life especially diarrhea. Table 3 shows that $85 \%$ people gave the exact answer when we asked them about the common disorder due to less intake of dietary fiber and the knowledge about these were higher among the urban people than rural people. This table also depicts that $60 \%$ and $28 \%$ of the respondents of the urban and rural areas respectively had the knowledge about On the other hand, 56\% rural people complain about acidity but only $2 \%$ people told about cancer when intake excess amount of fiber.

Table 4 shows that $92 \%$ people have a tendency to learn about dietary fiber and urban people were more curious than rural people. About $41 \%$ people acquire knowledge from books and papers where $21 \%, 16 \%$ and $22 \%$ people collect information from radio/TV, friends, and physicians respectively. Overall urban people prefer Books/Papers and rural people prefer Radio/TV. 90\% urban people take decision while they will take dietary fiber or not during disease condition but $31 \%$ people have no comments especially rural people (52\%).

Table2: Distribution of the respondents according to their nutritional and socio-economic condition and their knowledge about fiber.

\begin{tabular}{|c|c|c|c|}
\hline Characteristics & Urban (\%) & Rural (\%) & Total (\%) \\
\hline \multicolumn{4}{|l|}{ Socio-economic status } \\
\hline Higher class & $5(10)$ & $10(20)$ & $15(15)$ \\
\hline Middle class & $35(70)$ & $25(50)$ & $60(60)$ \\
\hline Lower class & $10(20)$ & $15(30)$ & $25(25)$ \\
\hline \multicolumn{4}{|l|}{ Nutritional status } \\
\hline Under weight & $5(10)$ & $16(32)$ & $21(21)$ \\
\hline Healthy & $37(74)$ & $30(60)$ & $67(67)$ \\
\hline Over weight & $8(16)$ & $4(8)$ & $12(12)$ \\
\hline \multicolumn{4}{|l|}{ Knowledge about dietary fiber } \\
\hline Yes & $48(96)$ & $37(74)$ & $85(85)$ \\
\hline No & $2(4)$ & $13(26)$ & $15(15)$ \\
\hline \multicolumn{4}{|l|}{ Knowledge of the role of dietary fiber } \\
\hline Yes & $30(60)$ & $12(24)$ & $42(42)$ \\
\hline No & $20(40)$ & $38(76)$ & $58(58)$ \\
\hline \multicolumn{4}{|l|}{ Knowledge about sources of dietary fiber } \\
\hline Carrots, Vegetables \& Fruits, Wheat's & $47(94)$ & $38(76)$ & $85(85)$ \\
\hline Milk, Meat, Fish & $2(4)$ & $9(11)$ & $11(11)$ \\
\hline Sugar, Rice, Water & $1(2)$ & $3(6)$ & $4(4)$ \\
\hline \multicolumn{4}{|c|}{ Knowledge of daily requirement of dietary fiber } \\
\hline Yes & $15(30)$ & $6(12)$ & $21(21)$ \\
\hline No & $35(70)$ & $44(84)$ & $69(69)$ \\
\hline \multicolumn{4}{|c|}{ Knowledge of dietary fiber more require for the following ages groups } \\
\hline Pregnancies Period & $7(14)$ & $10(20)$ & $17(17)$ \\
\hline Lactating Period & $1(2)$ & $3(6)$ & $4(4)$ \\
\hline Childhood & $3(6)$ & $6(12)$ & $9(9)$ \\
\hline
\end{tabular}


Table4: Distribution of the respondents according to their attitude and practices of dietary fiber.

\begin{tabular}{|c|c|c|c|}
\hline Characteristics & Urban (\%) & Rural (\%) & Total $(\%)$ \\
\hline \multicolumn{4}{|c|}{ Attitude to more learn of dietary fiber } \\
\hline Yes & $47(94)$ & $45(90)$ & $92(92)$ \\
\hline No & $3(6)$ & $5(10)$ & $8(8)$ \\
\hline \multicolumn{4}{|c|}{ Attitude of knowing information } \\
\hline Radio/TV & $7(14)$ & $14(28)$ & $21(21)$ \\
\hline Papers/Books & $30(60)$ & $11(22)$ & $41(41)$ \\
\hline Friends/Neighbors & $5(10)$ & $11(22)$ & $16(16)$ \\
\hline Health Center/Physicians & $8(16)$ & $14(28)$ & $22(22)$ \\
\hline \multicolumn{4}{|c|}{ Attitude of avoiding \& advising dietary fibers during diseases } \\
\hline Yes & $45(90)$ & $24(48)$ & $69(69)$ \\
\hline No & $5(10)$ & $26(52)$ & $31(31)$ \\
\hline \multicolumn{4}{|l|}{ Practice as laxative } \\
\hline Yes & $45(90)$ & $30(60)$ & $75(75)$ \\
\hline No & $5(10)$ & $20(40)$ & $25(25)$ \\
\hline \multicolumn{4}{|c|}{ Practice it to increase the activities of insulin } \\
\hline Yes & $47(94)$ & $17(34)$ & $64(64)$ \\
\hline No & $3(6)$ & $33(66)$ & $36(36)$ \\
\hline
\end{tabular}

This table also shows that $75 \%$ people use dietary fiber as laxatives where $90 \%$ are urban people. On the other hand, $94 \%$ urban people belief that dietary fiber increases insulin activity where $66 \%$ rural people are not.
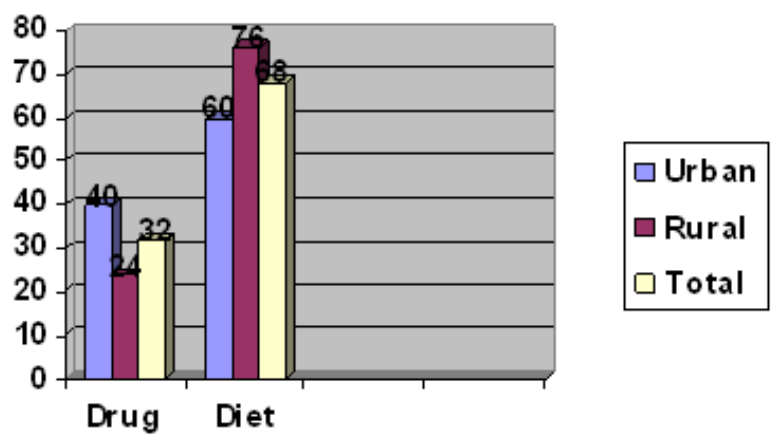

Fig.1: Compare between urban and rural population for preferring diet and drugs during various disease condition.

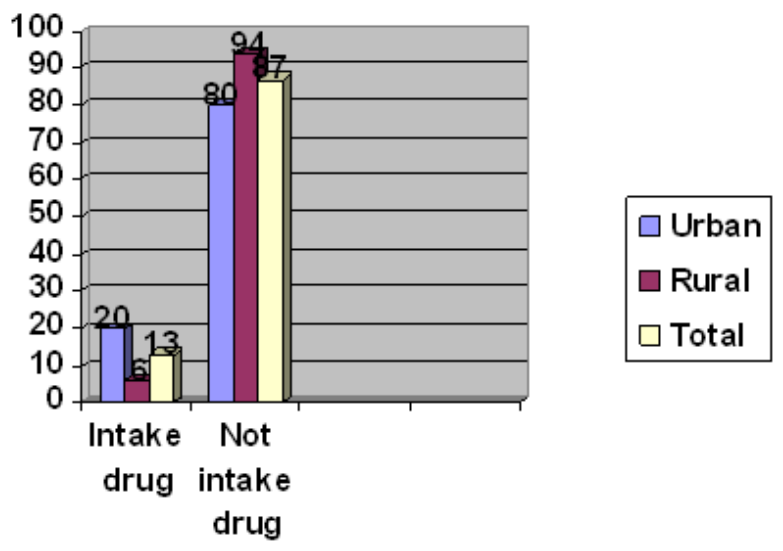

Fig.2: Practice of drug intake between urban and rural population during
Figure 1 represents that $68 \%$ people prefer diet during disease condition where $76 \%$ people were rural areas but $40 \%$ urban people prefer drugs. In our study, the rural people are more conscious to practice about the diet than urban people.

\section{Discussion}

In this study, knowledge, attitude \& practice (KAP) about dietary fiber among the people of the two selected areas of Bangladesh have been assessed. The knowledge about dietary fiber (DF) among the respondents in urban (96\%) is higher than rural (74\%) but $15 \%$ people have no idea about dietary fiber. Only $24 \%$ and $60 \%$ of the respondents of rural and urban people respectively know the role of dietary fiber in all stages of life especially in old ages. Among them $58 \%$ did not know the role of DF and 94\% urban people told the correct answer about dietary fiber but only $76 \%$ rural people told that vegetables and fruits are good sources of dietary fiber. So it seems that their overall knowledge about dietary fibers are not satisfactory. Only $21 \%$ people know about their daily requirements of fiber and 17\% respondents give emphasis on pregnancy period where only $4 \%$ people know the necessity of DF during lactation period. The major health problems of the people who intake less dietary fiber are constipation, piles, appendicitis, obesity, CVD, etc. that affects our national developments. About half of the respondents answered that it affects our mental and physical health. The knowledge about constipation and other related diseases among the respondents in both areas were very similar pattern (urban $90 \%$ and rural $80 \%$ ). Only $60 \%$ respondents in rural and $90 \%$ respondents in urban had the knowledge about the benefit of dietary fiber as laxatives. Comparatively the respondents of urban had slightly better 
knowledge about dietary fiber than the respondents of rural but the knowledge was not sufficient. Among the respondents $92 \%$ of both areas (urban $94 \%$ and rural $90 \%$ ) showed positive attitude to learn more about dietary fiber as it is important in all stages of life. But practice as laxative regularly among the respondents in urban people (90\%) are higher than rural $(60 \%)$. About $68 \%$ respondents in both areas (Urban $60 \%$ and Rural $76 \%$ ) consumed or practice diets regularly during diseases such as constipation. But $94 \%$ urban people and $34 \%$ rural people practice it to increase the activities of insulin. Only $31 \%$ people had a tendency to avoid it during disease condition and this tendency is higher in rural people $(52 \%)$. Whereas the attitude to prefer drugs is higher among urban (20\%) than rural people $(6 \%)$. The authors concluded that the knowledge, attitude, \& practices (KAP) of dietary fiber \& laxative are higher among urban people than rural people but the overall conditions of KAP is not satisfied to eliminate the disease related to dietary fiber. Successfully nutrition education (formal \& informal) with fruitful government policy is urgently needed to reduce the risk of diseases. As the rural areas of Bangladesh are less intake in dietary fiber and people are very less educated, applied nutrition programs in the large scale should be inaugurate immediately. Further a comprehensive study is needed in all geographical locations of the country to know the actual KAP of dietary fiber in whole Bangladesh.

\section{Conclusions}

In our study, urban people are more conscious about dietary fiber and its related diseases in compare to rural people but both people have a positive tendency to learn more about dietary fiber. So, more effective communication and consumer education is necessary to enhance fiber consumption from foods or supplements.

\section{Acknowledgement}

The authors are thankful to the Dept. of Applied Nutrition and Food Technology and to the participants of rural and urban people who shared their valuable time to perform our study.

Sk. Shahinur Rahman and Md. Tanvir Ahmed are equal contribution to prepare this manuscript.

[Sk. Shahinur Rahman $=$ Md. Tanvir Ahmed $]$

\section{References}

[1] James M. Lattimer and Mark D. Haub, (2010) Effects of Dietary Fiber and Its Components on Metabolic Health. Nutrients, 2, 1266-1289; doi:10.3390/nu2121266.

[2] Jones JR, Lineback DM, Levine MJ (2006) Dietary reference intakes: implications for fiber labeling and consumption: a summary of the International Life Sciences Institute North American FiberWorkshop, June 1-2, 2004. Washington, DC. Nutr Rev.64:31-38.
[3] Asp-Classification \& Methodology food carbohydrate as related to nutritional effect (1995) American journal of clinical nutrition 62: 9305 .

[4] FAO (1980) DF \& oils, food\& nutrition science, no, 20, FAO Rome.

[5] Lisa Brown, Bernard Rosner, Walter W Willett and Frank M Sacks (1999) Cholesterol-lowering effects of dietary fiber: a meta-analysis1,2. Am J Clin Nutr 69:30-42.

[6] Sibylle Kranz, Mary Brauchla, Joanne L. Slavin, and Kevin B. Miller (2012) What Do We Know about Dietary Fiber Intake in Children and Health? The Effects of Fiber Intake on Constipation, Obesity, and Diabetes in Children. Adv Nutr January Nutr vol. 3: 47-53. doi: 10.3945/an.111.001362.

[7] OAAC. AACC adopts oat bran definition (2010). Available online: http://www.aaccnet.org/news/pdfs/ OatBran.pdf (accessed on 12 October 2010)

[8] FAO/WHO Codex Alimentarius Commission (2010). Available online: http://www.codexalimentarius. net/download/standards/34/CXG_002e.pdf (accessed on 12 October 2010).

[9] James W Anderson, Pat Baird, Richard H Davis Jr, Stefanie Ferreri, Mary Knudtson, Ashraf Koraym, Valerie Waters, and Christine L Williams (2009) Health benefits of dietary fiber. Nutrition Reviews ${ }^{\circledR} \quad$ Vol. 67(4):188-205. doi:10.1111/j.1753-4887.00189.x

[10] Wong, J.M.; Jenkins, D.J. Carbohydrate digestibility and metabolic effects (2007) J. Nutr. 137, 2539S-2546S.

[11] US Department of Agriculture (USDA), US Department of Health and Human Services (2005). Dietary Guidelines for Americans. Washington, DC: USDA.

[12] Koh-Banerjee, P.; Franz, M.V.; Sampson, L.; Liu, S.M.; Jacobs, D.R.; Spiegelman, D.; Willett, W.; Rimm, E (2004) Changes in whole-grain, bran, and cereal fiber consumption in relation to 8-y weight gain among men. Am. J. Clin. Nutr. $80,1237-1245$.

[13] Story, J.A.; Furumoto, E.J.; Buhman, K.K (1997) Dietary fiber and bile acid metabolism - an update. Adv. Exp. Med. Biol. 427, 259-266.

[14] Truswell AS (1995) Dietary fibre and plasma lipids. Eur J Clin Nutr 49(suppl):S105-9.

[15] Kris-Etherton PM, Krummel D, Russell ME, et al (1988) The effect of diet on plasma lipids, lipoproteins, and coronary heart disease. J Am Diet Assoc 88:1373-400.

[16] Pereira MA, O'Reilly E, Augustsson K, et al (2004) Dietary fiber and risk of coronary heart disease: a pooled analysis of cohort studies. Arch Intern Med 164:370-376.

[17] Liu S, Stampfer MJ, Hu FB, et al (1999) Whole-grain consumption and risk of coronary heart disease: results from the Nurses' Health study. Am J Clin Nutr.70:412-419.

[18] Erkkila AT, Lichtenstein AH (2006) Fiber and cardiovascular disease risk: how strong is the evidence? J Cardiovasc Nurs $21: 3-8$.

[19] Streppel M.T.; Ocke M.C.; Boshuizen H.C.; Kok F.J.; Kromhout D. (2008) Dietary fiber intake in relation to coronary heart disease and all-cause mortality over $40 \mathrm{y}$ : The Zutphen Study. Am. J. Clin. Nutr. 88, 1119-1125. 
[20] Steffen LM, Jacobs DR Jr, Stevens J, Shahar E, Carithers T, Folsom AR (2003) Associations of whole-grain, refined grain, and fruit and vegetable consumption with risks of all-cause mortality and incident coronary artery disease and ischemic stroke: the Atherosclerosis Risk in Communities (ARIC) Study. Am J Clin Nutr.78:383-390.

[21] Whelton SP, Hyre AD, Pedersen B, Yi Y, Whelton PK, He J (2005) Effect of dietary fiber intake on blood pressure: a metaanalysis of randomized, controlled clinical trials. J Hypertens. 23:475-481.

[22] Meyer, K.A.; Kushi, L.H.; Jacobs, D.R., Jr.; Slavin, J.; Sellers, T.A.; Folsom, A.R (2000) Carbohydrates, dietary fiber, and incident type 2 diabetes in older women. Am. J. Clin. Nutr. 71, 921-930.

[23] Montonen J, Knekt P, Jarvinen R, Aromaa A, Reunanen A (2003) Whole-grain and fiber intake and the incidence of type 2 diabetes. Am J Clin Nutr. 77:622-629.

[24] Anderson JW, Zeigler JA, Deakins DA, et al (1991) Metabolic effects of high-carbohydrate, high-fiber diets for insulindependent diabetic individuals. Am J Clin Nutr. 54: 936-943.

[25] Tucker, L.A.; Thomas, K.S (2009) Increasing total fiber intake reduces risk of weight and fat gains in women. $J$. Nutr. 139, 576-581.

[26] Lairon D, Arnault N, Bertrais S, et al (2005) Dietary fiber intake and risk factors for cardiovascular disease in French adults. Am J Clin Nutr. 82:1185-1194.

[27] Petruzziello L, Iacopini F, Bulajic M, Shah S, Costamagna G (2006) Review article: uncomplicated diverticular disease of the colon. Aliment Pharmacol Ther. 23:1379-1391.

[28] Connor WE (1990) Dietary fiber nostrum or critical nutrient N, Engl Jmed 322, 193-5.

[29] Brown L, Rosner B, Willett WW, Sacks FM (1999) Cholesterollowering effects of dietary fiber: a meta-analysis. Am J Clin Nutr. 69:30-42.

[30] Whelton SP, Hyre AD, Pedersen B, Yi Y, Whelton PK, He J (2005) Effect of dietary fiber intake on blood pressure: a meta-analysis of randomized, controlled clinical trials. J Hypertens 23:475-81.

[31] Streppel MT, Arends LR, van't Veer P, Grobbee DE, Geleijnse JM (2005) Dietary fiber and blood pressure: a meta-analysis of randomized placebo-controlled trials. Arch Intern Med 165:150-6.

[32] Keenan JM, Pins JJ, Frazel C, Moran A, Turnquist L (2002) Oat ingestion reduces systolic and diastolic blood pressure in patients with mild or borderline hypertension: a pilot trial. J Fam Practice 51:369-375.

[33] Martinette T Streppel, Marga C Ocké, Hendriek C Boshuizen, Frans J Kok, and Daan Kromhout (2008) Dietary fiber intake in relation to coronary heart disease and all-cause mortality over 40 y: the Zutphen Study 1,2,3. Am J Clin Nutr 88 (4): $1119-1125$.

[34] WeickertMO, Mohlig M, Schofl C, et al (2006) Cereal fiber improves whole-body insulin sensitivity in overweight and obese women. Diabetes Care 29:775-780.

[35] Anderson JW, Randles KM, Kendall CWC, Jenkins DJA
(2004) Carbohydrate and fiber recommendations for individuals with diabetes: a quantitative assessment and meta-analysis of the evidence. J Am Coll Nutr. 23:5-17.

[36] Lu ZX,Walker KZ, Muir JG, Mascara T, O’Dea K (2000) Arabinoxylan fiber, a product of wheat flour processing, reduces the postprandial glucose response in normoglycemic subjects. Am J Clin Nutr. 71:1123-1128.

[37] Cummings JH (2001) The effect of dietary fiber on fecalweight and composition. In: Spiller G, ed. Dietary Fiber in Human Nutrition. Boca Raton, FL: CRC Press:183-252.

[38] Howarth NC, Saltzman E, Roberts SB (2001) Dietary fiber and weight regulation. Nutr Rev 59:129-39.

[39] Birketvedt GS, Shimshi M, Erling T, Florholmen J (2005) Experiences with three different fiber supplements in weight reduction. Med Sci Monit. 11:15-18.

[40] Du, H.D.; van der A, D.L.; Boshuizen, H.C.; Forouhi, N.G.; Wareham, N.J.; Halkjaer, J.; Tjonneland, A.; Overvad, K.; Jakobsen, M.U.; Boeing, H.; et al (2010) Dietary fiber and subsequent changes in body weight and waist circumference in European men and women. Am. J. Clin. Nutr. 91: 329-336.

[41] Watzl B, Girrbach S, Roller M (2005) Inulin, oligofructose and immunomodulation. Br J Nutr. 93(Suppl 1):S49-S55.

[42] Ma, Y.S.; Griffith, J.A.; Chasan-Taber, L.; Olendzki, B.C.; Jackson, E.; Stanek, E.J.; Li, W.J.; Pagoto, S.L.; Hafner, A.R.; Ockene, I.S (2006) Association between dietary fiber and serum C-reactive protein. Am. J. Clin. Nutr. 83: 760-766.

[43] Bo S, Durazzo M, Guidi S, et al (2006) Dietarymagnesium and fiber intakes and inflammatory and metabolic indicators in middle-aged subjects from a population-based cohort. Am J Clin Nutr. 84:1062-1069.

[44] Esposito, K.; Nappo, F.; Giugliano, F.; Di Palo, C.; Ciotola, M.; Barbieri, M.; Paolisso, G.; Giugliano, D (2003) Meal modulation of circulating interleukin 18 and adiponectin concentrations in healthy subjects and in patients with type 2 diabetes mellitus. Am. J. Clin. Nutr. 78, 1135-1140.

[45] Johnsen SP, Overvad K, Stripp C, Tjonneland A, Husted SE, Sorensen HT (2003) Intake of fruit and vegetables and the risk of ischemic stroke in a cohort of Danish men and women. Am J Clin Nutr. 78:57-64.

[46] Roberfroid MB (2005) Introducing inulin-type fructans. Br J Nutr. 93(Suppl 1):S13-S25.

[47] Cummings JH (2001) The effect of dietary fiber on fecalweight and composition. In: Spiller G, ed. Dietary Fiber in Human Nutrition. Boca Raton, FL: CRC Press: 183-252.

[48] Martinette T Streppel, Marga C Ocké, Hendriek C Boshuizen, Frans J Kok, and Daan Kromhout (2008) Dietary fiber intake in relation to coronary heart disease and all-cause mortality over 40 y: the Zutphen Study 1,2,3. Am J Clin Nutr. 88 (4): 1119-1125.

[49] Martin O. Weickert and Andreas F. H. Pfeiffer (2008) Metabolic Effects of Dietary Fiber Consumption and Prevention of Diabetes. J. Nutr. 138 (3): 439-442.

[50] Park, Y.; Brinton, L.A.; Subar, A.F.; Hollenbeck, A.; Schatzkin, A (2009) Dietary fiber intake and risk of breast cancer in postmenopausal women: The National Institutes of Health-AARP Diet and Health Study. Am. J. Clin. Nutr. 90: 
664-671.

[51] Nangia-Makker, P.; Hogan, V.; Honjo, Y.; Baccarini, S.; Tait, L.; Bresalier, R.; Raz, A (2002) Inhibition of human cancer cell growth and metastasis in nude mice by oral intake of modified citrus pectin. J. Natl. Cancer Inst. 94: 1854-1862.

[52] Young, G.P.; Hu, Y.; Le Leu, R.K.; Nyskohus, L (2005) Dietary fibre and colorectal cancer: A model for environment-gene interactions. Mol. Nutr. Food Res. 49: 571-584.

[53] Adlercreutz, H.; Hamalainen, E.; Gorbach, S.L.; Goldin, B.R.; Woods, M.N.; Brunson, L.S.; Dwyer, J.T (1987) Association of Diet and Sex-Hormones in Relation to Breast-Cancer. Eur. J. Cancer Clin. Oncol. 23: 1725-1726.

[54] Meyer, K.A.; Kushi, L.H.; Jacobs, D.R.; Slavin, J.; Sellers, T.A.; Folsom, A.R. (2000) Carbohydrates, dietary fiber, and incident type 2 diabetes in older women. Am. J. Clin. Nutr. 71: 921-930.

[55] Schulze, M.B.; Liu, S.; Rimm, E.B.; Manson, J.E.; Willett, W.C.; Hu, F.B (2004) Glycemic index, glycemic load, and dietary fiber intake and incidence of type 2 diabetes in younger and middle-aged women. Am. J. Clin. Nutr. 80: 348-356.

[56] Montonen, J.; Knekt, P.; Jarvinen, R.; Aromaa, A.; Reunanen, A. (2003) Whole-grain and fiber intake and the incidence of type 2 diabetes. Am. J. Clin. Nutr. 77: 622-629.

[57] Jenkins, D.J.A.; Kendall, C.W.C.; Augustin, L.S.A.; Martini, M.C.; Axelsen, M.; Faulkner, D.; Vidgen, E.; Parker, T.; Lau, H.; Connelly, P.W.; Teitel, J.; Singer, W.; Vandenbroucke, A.C.; Leiter, L.A.; Josse, R.G. ( 2002) Effect of wheat bran on glycemic control and risk factors for cardiovascular disease in type 2 diabetes. Diabetes Care 25: 1522-1528. 